\title{
REFLECTION-IN-ACTION WHEN DESIGNING ORGANIZATIONAL PROCESSES: PROTOTYPING WORKSHOPS FOR COLLECTIVE REFLECTION-IN-ACTION
}

\author{
Wegener, Frithjof Eberhard; Guerreiro Gonçalves, Milene; Dankfort, Zoë \\ Delft University of Technology, Faculty of Industrial Design Engineering
}

\begin{abstract}
In this paper on designing organizational processes, we combine insight on reflection-in-action with the role of reflection and experimenting from the organizational routine dynamics literature. Illustrated through a case at a strategy consultancy, we show how a prototyped workshop can elicit reflection-inaction when designing organizational processes. The artifacts used in the prototyped workshop made previous implicit assumptions about the work more explicit. This led to on the spot reflection-in-action of how to improve the prototype. This shows how collective reflection-action can be created by creating a space for reflection, that simultaneously allows for experimentation. Future research between design science and organizational science would thus be fruitful when studying the role of collective reflectionin-action when prototyping organizational processes.
\end{abstract}

Keywords: Organizational processes, Design process, Collaborative design, Routine design, Affordances

\section{Contact:}

Wegener, FE

Delft University of Technology

Product Innovation Management

The Netherlands

f.e.wegener@tudelft.nl

Cite this article: Wegener, F.E., Guerreiro Gonçalves, M., Dankfort, Z. (2019) 'Reflection-in-Action When Designing Organizational Processes: Prototyping Workshops for Collective Reflection-in-Action', in Proceedings of the 22nd International Conference on Engineering Design (ICED19), Delft, The Netherlands, 5-8 August 2019. DOI:10.1017/ dsi.2019.131 


\section{INTRODUCTION}

(Re)design of organizational processes is an interdisciplinary issue, as both the insights from design as well as from organizational science are relevant (Yoo et al., 2006). The organizational element comes from organizing being about aligning a purpose with the collaboration needed to achieve it (Greenwood and Miller, 2010; Greenwood and Prakash, 2009; Lorino and Mourey, 2015). This means that organizing can be as small as a workshop and as big as an international corporation. From the design field perspective, design of organizational processes has gained renewed interest, as designers look beyond visual and product design to higher order of design such as service design, organization design or system design. (Buchanan, 2015). As example, designers might be involved in redesigning their own processes of product design, innovation (Junginger, 2008), or service design (Junginger, 2015), where designers also have to redesign organizational processes to some degree. For designers, it is relevant to understand the managerial and organizational issues they have to deal with, for example when designing and innovating in larger organizations where viability is often an issue. With the role of designers being extended towards designing organizational processes, designers could thus be helped with a refined understanding of organizations, as the design of organizational processes is bound to run into organizational challenges as well (Junginger, 2015). These interdisciplinary challenges make designing organizational processes interesting for both designers (Buchanan, 2007; 2015; Junginger, 2008; 2015) as well as organizational scientists (Feldman et al., 2016; Pentland and Feldman, 2008).

This paper addresses the role of collective reflection-in-action (Schön, 1983; Yanow and Tsoukas, 2009) that can be elicited when prototyping organizational processes. To illustrate our conceptual ideas, we use a strategic design case. A master design student (Dankfort, 2018) was tasked with redesigning the strategy making process of a strategy consultancy, by adding design practices that help engage employees with strategy. While the overall process is described in the master thesis of the student (Dankfort, 2018), we focus our analysis on a surprising collective reflection moment that occurred within the strategy consultancy. As a surprise to both the master student and the employees of the strategy consultancy, the evaluation moment of a prototype for designing workshops, led to unexpected insights about implicit assumptions underlying the work of the strategy consultants. By showing how a prototyped workshop lead to making previously implicit assumptions about the work explicit, this case study illustrates the importance of collective reflection (Buchner and Langley, 2016; Dittrich, Guerard and Seidl, 2016; Yanow and Tsoukas) when designing organizational processes.

Designing such organizational processes aiming at novelty are also of interest to organizational science. Here, the study of organizational processes within organization science is largely subsumed under the concept of organizational routines. Routines are defined as "repetitive, recognizable patterns of interdependent actions that involve multiple actors" (Feldman and Pentland, 2003; HowardGrenville, 2005; Parmigiani and Howard-Grenville, 2011). Such definition might make routines sound like static, mindless and rigid repetitions of activities, when in reality, this is not the case. This would explain why the design of organizational processes often focuses on redesigning checklists, changing rules and procedures or reinforcing new organizational processes with software, hoping that redesigning such artefacts will lead to the desired changes in the routine (Pentland and Feldman, 2008). More recent work has reinforced that routines are effortful accomplishments, as people have to deal with changing circumstances while trying to achieve their goals (Feldman, 2000; Feldman and Pentland, 2003; Feldman et al., 2016) and how 'alive' routines can be (Cohen, 2007). An important insight here is the role of reflection (Dittrich et al., 2016) and its interplay with experimentation when redesigning routines (Bucher and Langley, 2016). The importance of experimentation in organizational routines is in line with the understanding of design as an iterative and experimental process, where implementation becomes part of the design process (Norman and Stappers, 2015).

The remainder of the article first introduces routine dynamics, in order to discuss the topic of routine design. Here we highlight the role of reflection and experimentation. These issues are illustrated with a vignette from our case. We round off the paper by a discussion and several avenues for potential future research. The paper closes with our conclusion, that design researchers and organizational scholars might most fruitful engage with each other by studying the interaction of reflection and experimentation when designing organizational processes. 


\section{ROUTINES AND THE ROLE OF REFLECTION AND EXPERIMENTATION IN DESIGNING ROUTINES}

Routines originate from discussions in economics of how organizations learn over time and how that learning is manifested through memory (Nelson and Winter, 2002). Routines were advanced as an explanation of how companies gradually learn which processes and actions work best for their chosen goal. While helpful initially, such a perspective on organizational processes reinforced a static view of routines as consisting of the same steps every time, neglecting the experience of actors that have to constantly adapt to changing situations in which to perform a routine (Feldman et al., 2016; Pentland and Feldman, 2008).

\subsection{Routines, artefacts \& boundary objects}

Earlier work on routines focused on the roles of artefacts in routines. Artefacts can play an important role to stabilize routines as the ostensive aspects of routines (Leutenegger et al., 2018). Such artefacts can be guidelines, visualizations of routines or a flowchart. The (re)design of routines can thus address the design of such artefacts of routines. On the other hand, artefacts can also play an important role within the routine. Here, a check-list can help users remember which actions to take and to check if the actions were already taken. A specific form of artefact would be boundary-objects.Boundary objects help people by transferring, translating and transforming knowledge across boundaries (Carlile, 2002; 2004). For routines, an important form of boundary objects are visual representations, rules, checklists and other forms of representations of the routine. This has led to routine design often focusing on redesigning such representations of routines (Cohen, 2007). The challenge here though is that just redesigning the representation of a routine does not necessarily mean that the actual performance of the routine changes (Pentland and Feldman, 2008). Understanding the internal dynamics of routines are particularly important when we aim to "influence, design or manage" routines (Pentland and Feldman, 2005, p. 793). To grasp routines more deeply and to build better theory about how to design them requires an understanding of the underlying processes (Sutton and Staw, 1995). A central challenge of routines and changing them is the 'puzzle of recursiveness' (Feldman, 2003). Routines and the actions that make up the routines have existing relationships, that reinforce the status quo. Then how can one change a routine, despite this tendency to remain at the status quo?

\subsection{From routine dynamics to routine design}

How routines change has become the focus of research for the last 20 years. While previous research had taken a rather static account of routines as repeated patterns of actions, this ongoing stream of research looks more and more at the dynamics of routines and therefore at how routines change over time. Here the interaction between the representational patterns of routines (such as visualizations and others forms of representation of routines) and the performative aspects (as the specific instances where a routine is performed) play an important role (Pentland and Feldman, 2005). More specifically, it is important to investigate how changing representations of a routine might change the actual performance, but also how specific performances of routines might change the overall routine (Feldman and Pentland, 2003). Thus, an interesting avenue for research is how the redesign of routine artefacts influences the actual performance of routines (e.g. Glaser, 2016).

More recent work on routine dynamics has explored the co-creation and co-design of different actors together changing a routine, creating a routine and even designing a routine and therefore touching upon larger topics of changing an organization (Becker et al., 2005). Below we introduce several studies that have explored efforts of people to change existing routines. While using different concepts to describe these efforts, they are all related to aspects of routine design.

Glaser (2017) has studied the introduction of algorithms to the organizational processes of a police force. Glaser looked at design performances as the organizations redesigned artefacts to change a routine. This work highlighted the dynamic nature of routine design, as artefacts, members of the organizations, theories underlying their choices and the specific actions available interacted with each other.

Bapuji et al. (2018) have studied the redesign of a towel change routine in a hotel. Their work focused on how bringing in the understanding of the stakeholders involved (e.g., maid's changing the towels) can be beneficial when redesigning a routine. At the same time, the authors highlighted the challenges of having to design organizational processes where the hotel guests, as users, have to play their role as well. Leutenegger, Tuckermann, Gutzan and Rüegg-Stürm (2018) studied the change of a routine in a 
hospital, by focusing on the role of designing the ostensive aspect of a routine and the challenges of doing so when different stakeholders are involved.

All these studies have introduced different aspects and challenges of intentionally changing routines, but where these studies often lack is in the detailed description of the actual designing of the routine, especially the role of experimentation and prototyping that is so important to design (Coughlan et al., 2007).

\subsection{Reflective spaces \& experimental spaces in routine change}

To get a better understanding of how routines are designed, it is beneficial to look at reflective and experimental spaces. Either by intentionally optimization of its parts or by accidently changing routines, more fundamental change of routines requires reflection. Earlier sociological research had indicated the important role of spaces for organizational change (Kellogg, 2009). In the following we introduce more recent work on the roles of spaces that indicates the importance of spaces for reflection, spaces for experimentation and the interaction of these in routine change.

Dittrich, Guérard and Seidl (2016) have shown the role of reflective talk in routine change, as people engaged in routine design need to be able to step back from their current ways of working in order to find new ways of working. Such reflective talk is aided through reflective spaces.

While reflective spaces are more related to reflection-on-action (Bucher and Langley, 2016; Schön, 1983), experimental spaces relate more to the performative aspect of routines and the reflection-inaction (Schön, 1983; Yanow and Tsoukas, 2009) of active experimentation within a routine. Reflective spaces allow for various forms of boundaries to detach oneself from daily work, needed to reflect. Experimental spaces are intended to bring the actors back into the setting of the workspace and safely experiment within the boundaries of their work (Bucher and Langley, 2016).

Thus, rather than only engaging in reflection-on-action by looking backwards at actions taken and reflecting on these, it is important to explore routine change from inside through studying the reflection-in-action that goes on as people experiment with routines. Here, more recent work on routine dynamics looks more explicitly at attempts to change routines. Such work has looked at routine change and the role of reflective talk (Dittrich et al., 2016), intentions (Dittrich and Seidl, 2018), interplay of reflective and experimental spaces (Bucher and Langley, 2016) and the role of designing artefacts (Glaser, 2017).

\subsection{Experimentation for routine design}

Recent examples of work highlighting this internal experimentation of routines can be found in Turner and Rindova (2012), D'Adderio (2014), and Rerup and Feldman (2011). These studies show that a challenge of routine design is that when the routine changes, people need to adapt their understandings of the routine (Bapuji et al., 2018), their role (Dionysiou and Tsoukas, 2013), the practices they use (Pentland and Feldman, 2008), and their underlying beliefs (Cohen, 2007) in light of the changing organizational context (Dionysiou and Tsoukas, 2013) and the routine (Bucher and Langley, 2016). These issues require that part of designing a routine is enactment (Bucher and Langley, 2016; Simpson and Lorino, 2016) of the new routine through experimentation. An example of such experimentation is the vignette that follows. We explore this issue using a case study, originated from the master thesis of the third author (Dankfort, 2018), by delving deeper into the role of reflection-in-action during the design review of the prototyped workshop.

\section{CASE STUDY: EVALUATING A TOOLKIT AS A MOMENT OF COLLECTIVE REFLECTION-IN-ACTION}

Our case stems from the master thesis project of the third author. We purposefully selected the evaluation of the toolkit (see Figure 1), which was a theoretically important moment in the single case study (Yin, 2013). This was done to gain a better qualitative understanding of how and why the collective reflection moment occurred and what role reflection-in-action played here to illustrate the conceptual discussion in the previous section. The evaluation moment of the third author was taped and the sections relevant to our theoretical discussion transcribed. A follow-up online survey was done by the third author, to elicit extra feedback from the participants on the prototype and the evaluation session. 


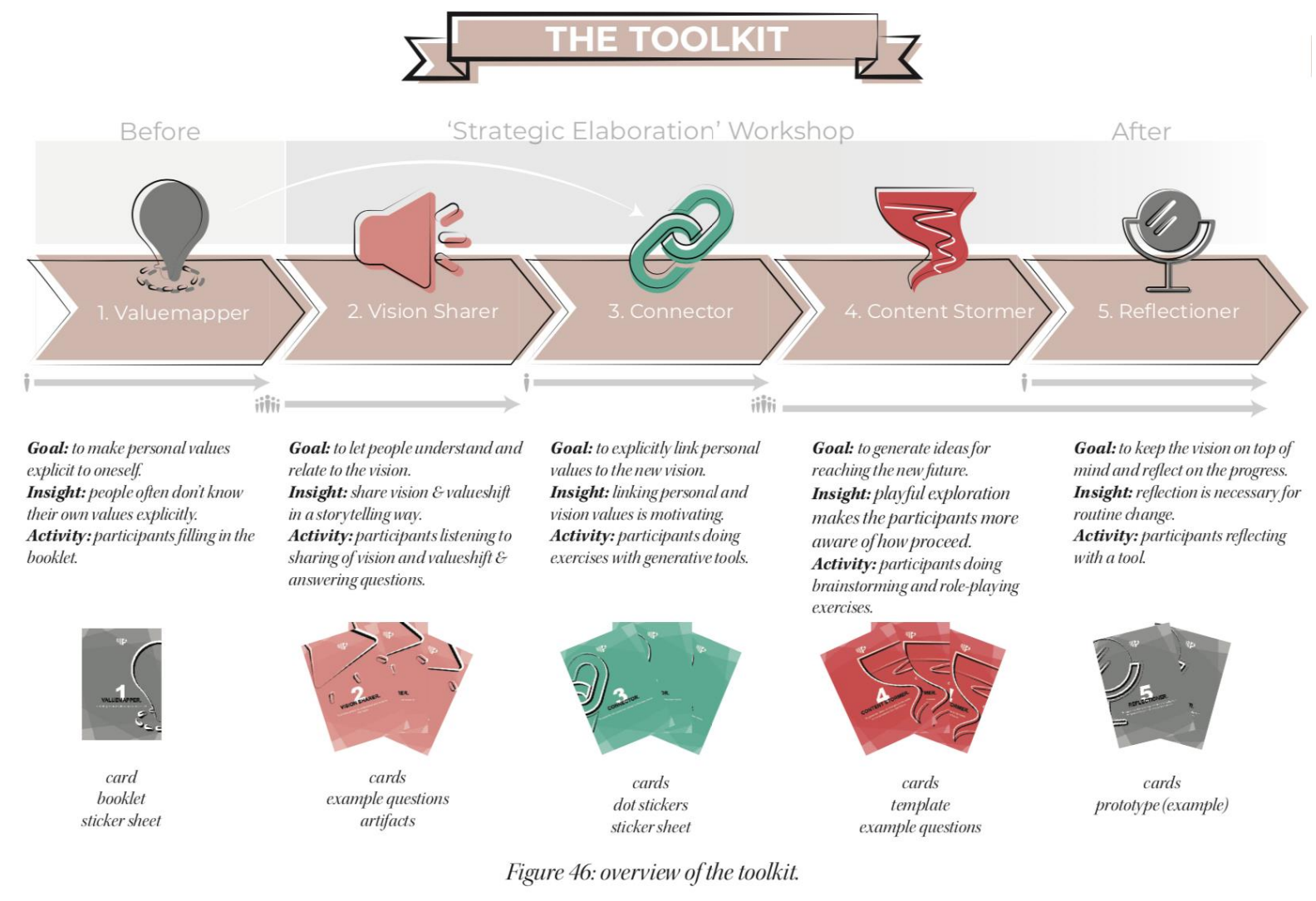

Figure 1: Overview of toolkit (Dankfort, 2018)

Our case particularly addresses the evaluation session of the prototype of the toolkit, developed for the purpose of supporting strategy implementation via visual storytelling (see Figure 1). The prototype was tested during a session of 1,5 hours, with five members of the strategy consultancy and the third author/designer of the toolkit.

The evaluation of the prototype toolkit was set-up so that different members of the strategy consultancy could engage with the toolkit and each other to elicit reflection and feedback. Besides using the prototype in a realistic situation, one of the main goals of the evaluation was to reflect on and change the routine of the strategy consultancy itself:

"As has been seen during the internal analysis, [the strategy consultancy] has some opportunities to improve their way-of-working by incorporating design skills (tools in the toolkit). This means changing their own routine. Next to being engaged with the toolkit, they have to know what their routine currently is, reflect on it and see the added value of using the toolkit. Although this is something that can only truly be measured over time, during the evaluation the discussion can indicate how willing and able they are to change their routine."

The set-up of the evaluation was three-fold: initially, they used the toolkit, followed by a feedback session of using the specific tool on values and finally, the participants had to fill an online survey. Participants received a program and a digital toolkit to familiarize themselves beforehand. The group was tasked to design a particular workshop.

They were split in two groups, one applying the toolkit to a previous client, the other group applying the toolkit to a current client of the consultancy. This made the case realistic for the participants. The master student started out with instruction, stating to work "as if you were about to design the workshop". This was done to put the participants into a realistic situation of actually having to go about using the tool, eliciting reflection-in-action, rather than reflection-on-action (Schön, 1983). At some point later, a participant wonders:

Participant 1: "so we just practice... designing a workshop?"

Master Thesis Student: "Yes"

P1: "and we let you know when we run into things that make us go 'huh'?"

M: "Yes"

P1: "and we give green light when it works, yes?" 

M: "Exactly"
P1: "With the example of [current project] in mind?"
M: "Yes"

While the first two steps of the toolkit seemed to work, during the third step (see Figure 2), the use of cards with questions about values led to some surprising "huh" moments. The use of the tool starts a discussion around the current status of values in the routine of the strategy consultant itself:

Participant 1: "Maybe the questions need to be different (...) if we already find it difficult (...) struggle to understand values here... in my experience if you ask people about values they get stuck..."

Participant 2: "even for people like us that are consciously busy with these abstract words and things [to talk about values]"

P1: "in the reflection.. but if you ask the question much simpler... in the end you achieve exactly the same"

P2: "I assumed that we always work explicitly with changing organizational values..."

Here the assumption about the goal being the change of organizational values is questioned during step 3 (see Figure 2). The discussion around values continues. As a participant later remarks in the online survey:

Participant 3: "You noticed that in the Friday discussion. Your toolkit clearly stimulated a good discussion!"

In the evaluation of this prototyping session, the master student noted that the participants:

"could understand the cards' content quite easily and were playing around with the cards, pointing to them while discussing (...) The content of the toolkit provided quite some discussion. (...) team had different definitions of value among themselves. (...) [They] already thought it was difficult for themselves to think about values, let alone for the clients' employees who don't regularly think that abstractly in their work."
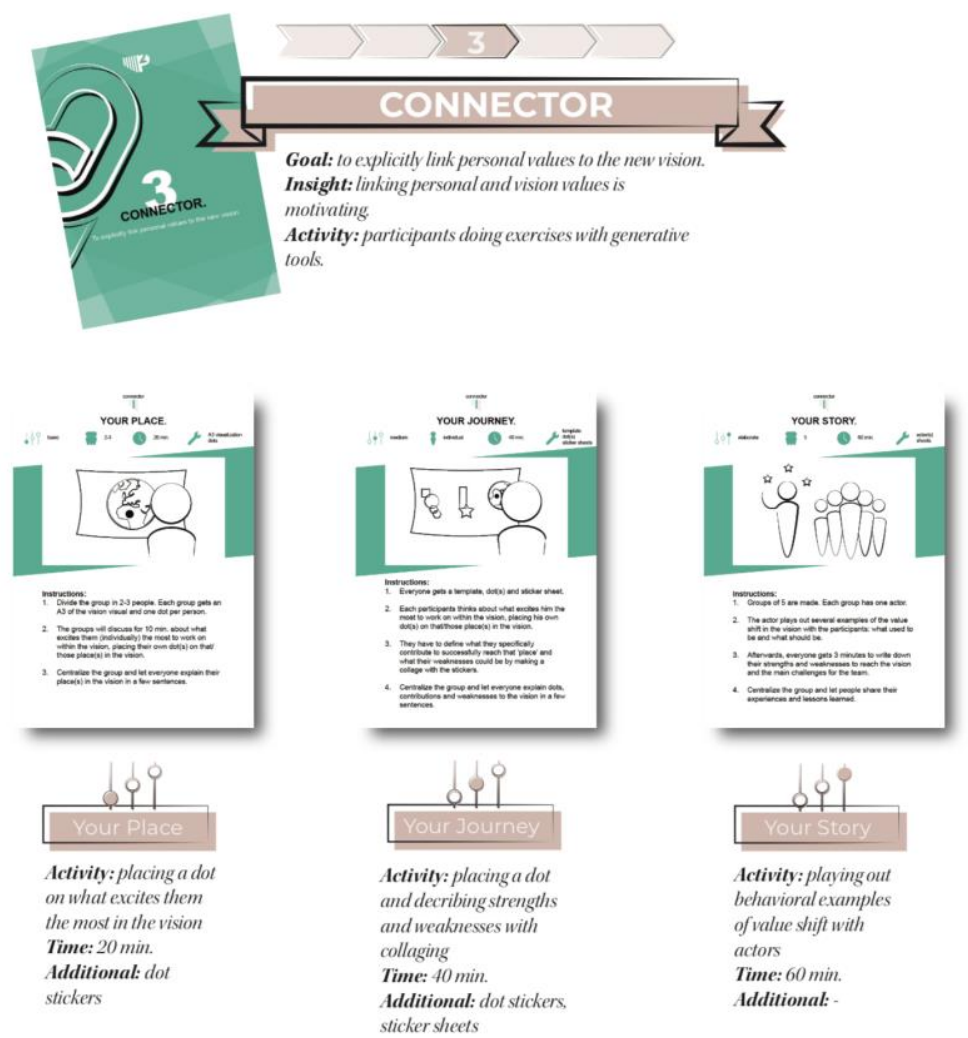

Figure 2: Phase 3 (Dankfort, 2018)

\section{FINDINGS}

What we see in this short case, is the role that the prototyped workshop played in getting the group to reflect together on the role of values in their current routine. As known from literature, artefacts can 
act as boundary objects (Carlile, 2002; 2004) to transform knowledge. The actual use of the prototype, as a form of experiment, made differences between the assumptions about their work explicit. In this case, the role of changing organizational values was questioned. In using the tool, the group started to reflect, indicating reflection-in-action (Schön, 1983). Thus, even while the participants had gone through many of these workshops before, the role of values had not before come up this explicit. By having the prototyped workshop as a form of boundary object, the underlying assumptions about their work came to the forefront.

We found that several aspects of the evaluation moment helped lead to this outcome. The explicitness of a physical toolkit helps by acting as a boundary object (Carlile, 2002; 2004). Rather than abstractly giving feedback, engaging the group in the concrete with a realistic situation of having to design a workshop for a client seemed to elicit realistic surprises (in this case about the role of values). At the same time, since the moment was not with an actual client, it seemed closer to an experimental space as described in Bucher and Langley (2016). This allowed the participants to engage in reflection-inaction (Yanow and Tsoukas, 2009) on their routine and the underlying implicit assumptions, leading to a collective reflection moment.

This finding is supported by the online survey, where the statement: "The toolkit helps with conscious reflection-on(-action) and -in(- action) the current [strategy consultant] routine." received one of the highest scores. Participants noted that they valued how the toolkit sparked discussion about their own routine, in this case, the routine of workshop preparations. Next to this, participants thought this toolkit would help with reflection-on-action of a workshop afterwards, by allowing the group to more explicitly reflect on the pattern of their routine.

We see therefore how the use of a prototype is able to elicit collective reflection-in-action, leading to participants using the toolkit as a boundary object to become aware of their underlying assumptions about their own routine.

\section{DISCUSSION}

In our case, what was intended to be an experimental space by using a prototype, turned out to be an opportunity for a collective reflection (Yanow and Tsoukas, 2009) moment, triggered by the surprising insight that the participants' assumptions about values were different. It seems that, rather than Bucher and Langley (2016) indicating that reflective spaces and experimental spaces are different, at least within this specific case the participants were able to experiment and reflect at the same time.

Regarding the role of the prototypes as boundary objects, we saw that making the routine of the group explicit, allowed them to reflect on it in a different way than before. The action of engaging in "playing" with the cards and "pointing" at the cards seemed to help the group reflect with each other as a form of reflection-in-action.

Our findings seem to indicate that it is beneficial to create space for both reflection and experimentation during routine design. Particularly, it is preferable to allow participants to engage with prototypes in a way that elicits reflection-in-action, seeing emergent surprises as interesting learning opportunities.

\section{FUTURE RESEARCH}

Next, we want to highlight two potentially interesting avenues for design researchers to engage in for future research on designing organizational processes. What are current questions on designing routines?

\subsection{How are routines born?}

In our case study, we described the redesign of an existing organizational process. Yet, sometimes the design of an organizational process starts from scratch. This relates to one of the current key questions in routine design, namely how routines are actually born (Howard-Grenville, 2005). While recent work has shed much light on the dynamics of routines when they already exist, we still miss a better understanding of how routines come into being. As with other research on emergence of the phenomenon of interest, one of the challenges here is how to study something that does not exist yet and how to ensure that you are there when it actually emerges (Fachin and Langley, 2018; Langley and Tsoukas, 2010; Langley et al., 2013). 


\subsection{How to elicit reflection-in-action during designing organizational processes?}

Extending the existing work on the importance of reflection in routine design (Dittrich et al., 2016) and its interplay with experimentation (Bucher and Langley, 2016), ) a next step would be to look at the possibility to elicit collective reflection-in-action, where participants can both experiment and reflect while engaged in the routine.

\section{CONCLUSION}

The aim of this paper was to reach a better understanding of how experimentation and reflection are essential elements to design routines and organizational processes. Our review of the literature highlighted that reflection and experimentation are crucial in redesigning organizational processes (Bucher and Langley, 2016). Rather than detached designing of the representations of pattern in routines, this calls for situated experimentation. We have found that reflection-in-action is important for the design of organizational processes and prototypes can help to elicit reflection-in-action (Schön, 1983). This is even more important, when the group manages to engage in collective reflection (Yanow and Tsoukas, 2009) during the testing of a prototype. We highlighted several avenues for future research, most notably studies that uncover from the inside how people redesign organizational processes and how reflection and experimentation can interact to elicit collective reflection-in-action. We hope that other design scholars are interested to take their insights into designing organizational processes to organizational science and, conversely, that designers welcome insights on (designing) organizational processes from the organizational science perspective.

\section{REFERENCES}

Ansell, C. (2012), "What is a 'Democratic Experiment'?", Contemporary Pragmatism, Brill, Vol. 9 No. 2, pp. $159-180$.

Ansell, C. and Boin, A. (2017), "Taming Deep Uncertainty: The Potential of Pragmatist Principles for Understanding and Improving Strategic Crisis Management", Administration \& Society, SAGE Publications, Los Angeles, CA, Vol. 153, pp. 1-34.

Bapuji, H., Hora, M., Saeed, A. and Turner, S. (2018), "How Understanding-Based Redesign Influences the Pattern of Actions and Effectiveness of Routines", Journal of Management, Vol. 24, pp. $014920631774425-31$.

Becker, M.C., Lazaric, N., Nelson, R.R. and Winter, S.G. (2005), “Applying organizational routines in understanding organizational change", Industrial and Corporate Change, Vol. 14 No. 5, pp. 775-791.

Boland, R.J. and Collopy, F. (Eds.) (2004), Managing as Designing, Stanford Business Books, Stanford, CA.

Brown, B., Buchanan, R., Doordan, D. and Margolin, V. (2007), "Introduction”, Design Issues, Vol. 24 No. 1, pp. 1-1.

Buchanan, R. (2007), "Introduction: Design and Organizational Change”, Design Issues, Vol. 24 No. 1, pp. 1-8.

Buchanan, R. (2015), "Worlds in the Making: Design, Management, and the Reform of Organizational Culture", She Ji: the Journal of Design, Economics, and Innovation, Vol. 1 No. 1, pp. 5-21.

Bucher, S. and Langley, A. (2016), "The Interplay of Reflective and Experimental Spaces in Interrupting and Reorienting Routine Dynamics", Organization Science, Vol. 27 No. 3, pp. 594-613.

Carlile, P.R. (2002), "A Pragmatic View of Knowledge and Boundaries: Boundary Objects in New Product Development", Organization Science, Informs, Vol. 13 No. 4, pp. 442-455.

Carlile, P.R. (2004), "Transferring, Translating, and Transforming: An Integrative Framework for Managing Knowledge Across Boundaries", Organization Science, Vol. 15 No. 5, pp. 555-568.

Cohen, M.D. (2007), "Reading Dewey: Reflections on the Study of Routine", Organization Studies, SAGE Publications, Vol. 28 No. 5, pp. 773-786.

Coughlan, P., Suri, J.F. and Canales, K. (2007), "Prototypes as (Design) Tools for Behavioral and Organizational Change", The Journal of Applied Behavioral Science, Vol. 43 No. 1, pp. 122-134.

Dankfort, Z. (2018), The Visual Storytelling Toolkit: A Way to Engage Employees with their Organization's Vision. M.Sc. Thesis. Delft University of Technology. Available at: http://resolver.tudelft.nl/uuid:0e85ba80-77fe-4ad9-ba5f-16d39d767960 (Accessed: 7 April 2019)

Deken, F., Carlile, P.R., Berends, J.J. and Lauche, K. (2016), "Generating Novelty Through Interdependent Routines: A Process Model of Routine Work", Organization Science, Vol. 27 No. 3, pp. orsc.2016.1051-21.

Dionysiou, D.D. and Tsoukas, H. (2013), "Understanding the (Re)Creation of Routines from Within: A Symbolic Interactionist Perspective", Academy of Management Review, Vol. 38 No. 2, pp. 181-205.

Dittrich, K. and Seidl, D. (2018), "Emerging Intentionality in Routine Dynamics: A Pragmatist View", Academy of Management Journal, Vol. 61 No. 1, pp. 111-138. 
Dittrich, K., Guérard, S. and Seidl, D. (2016), "Talking About Routines: The Role of Reflective Talk in Routine Change", Organization Science, Vol. 27 No. 3, pp. 678-697.

Fachin, F.F. and Langley, A. (2018), "Researching Organizational Concepts Processually: The Case of Identity", in Cassell, C., Cunliffe, A.L. and Grandy, G. (Eds.), The Sage Handbook of Qualitative Business and Management Research Methods: History and Tradition, pp. 308-345.

Farjoun, M., Ansell, C. and Boin, A. (2015), "PERSPECTIVE-Pragmatism in Organization Studies: Meeting the Challenges of a Dynamic and Complex World”, Organization Science, Vol. 26 No. 6, pp. 1787-1804.

Feldman, M.S. (2000), “Organizational Routines as a Source of Continuous Change”, Organization Science, Vol. 11 No. 6, pp. 611-629.

Feldman, M.S. (2015), "Routines As Process: Past, Present And Future”, in Organizational Routines and Process Organization Studies, pp. 1-34.

Feldman, M.S. and Pentland, B.T. (2003), "Reconceptualizing Organizational Routines as a Source of Flexibility and Change", Administrative Science Quarterly, Vol. 48 No. 1, p. 94.

Feldman, M.S., Pentland, B.T., D’Adderio, L. and Lazaric, N. (2016), "Beyond Routines as Things: Introduction to the Special Issue on Routine Dynamics", Organization Science, Vol. 27 No. 3, pp. 505-513.

Gibson, J.J. (2014), The Ecological Approach to Visual Perception, Psychology Press.

Glaser, V. L. (2017), Design Performances: How Organizations Inscribe Artifacts to Change Routines. Academy of Management Journal, Vol. 60 No. 6, pp. 2126-2154. http://doi.org/10.5465/amj.2014.0842

Greenwood, R. and Miller, D. (2010), Tackling design anew: Getting back to the heart of organizational theory. The Academy of Management Perspectives, Vol. 24 No. 4, pp. 78-88. http://doi.org/10.5465/AMP.2010.24.4.3655970.a

Hoekzema, J. and Geiger, D. (2018), "Disentangling Routine Interdependence: Blurry Boundaries and Dynamic Patterning.", presented at the 32th EGOS Colloquium.

Howard-Grenville, J.A. (2005), “The Persistence of Flexible Organizational Routines: The Role of Agency and Organizational Context”, Organization Science, Vol. 16 No. 6, pp. 618-636.

Junginger, S. (2008), "Product Development as a Vehicle for Organizational Change", Design Issues, The MIT Press, Vol. 24 No. 1, pp. 26-35.

Junginger, S. (2015), “Organizational Design Legacies and Service Design”, The Design Journal, Vol. 18 No. 2 , pp. 209-226.

Kellogg, K.C. (2009), “Operating Room: Relational Spaces and Microinstitutional Change in Surgery”, American Journal of Sociology, The University of Chicago Press, Vol. 115 No. 3, pp. 657-711.

Kremser, W. and Schreyögg, G. (2016), "The Dynamics of Interrelated Routines: Introducing the Cluster Level”, Organization Science, Vol. 27 No. 3, pp. 698-721.

Langley, A. and Tsoukas, H. (2010), "Introducing 'Perspectives on Process Organization Studies"”, in Process, Sensemaking, and Organizing, Oxford University Press, pp. 1-26.

Langley, A., Smallman, C., Tsoukas, H. and Van de Ven, A.H. (2013), "Process Studies of Change in Organization and Management: Unveiling Temporality, Activity, and Flow", Academy of Management Journal, Academy of Management, Vol. 56 No. 1, pp. 1-13.

Leutenegger, C., Tuckermann, H., Gutzan, S. and Ruegg-Sturm, J. (1997), "Organizational routine design in a hospital: a narrative-based study of ostensive routine dimensions in the making", presented at the 10th International Symposium on Process Organization Studies, Halidiki, Greece.

Levina, N. and Vaast, E. (2018), "Turning Collaboration into Transaction: A Case of Intranet Use in BoundarySpanning Practices", presented at the 38th Annual Hawaii International Conference on System Sciences, IEEE, pp. 245a-245a.

Lok, J. and de Rond, M. (2013), "On the Plasticity of Institutions: Containing and Restoring Practice Breakdowns at the Cambridge University Boat Club”, Academy of Management Journal, Vol. 56 No. 1, pp. 185-207.

Lorino, P. and Mourey, D. (2013), The experience of time in the inter-organizing inquiry: A present thickened by dialog and situations. Scandinavian Journal of Management, Vol. 29 No. 1, pp. 48-62. http://doi.org/10.1016/j.scaman.2012.11.011

Miller, D., Greenwood, R. and Prakash, R. (2009), What Happened to Organization Theory? Journal of Management Inquiry, Vol. 18 No.4, pp. 273-279. http://doi.org/10.1177/1056492609344672

Nelson, R.R. and Winter, S.G. (2002), "Evolutionary Theorizing in Economics", The Journal of Economic Perspectives, American Economic Association, Vol. 16 No. 2, pp. 23-46.

Norman, D. A. and Stappers, P. J. (2015), "DesignX: Complex Sociotechnical Systems". She Ji: the Journal of Design, Economics, and Innovation, Vol. 1 No. 2, pp. 83-106. http://doi.org/10.1016/j.sheji.2016.01.002

Orlikowski, W.J. (1992), “The Duality of Technology: Rethinking the Concept of Technology in Organizations", Organization Science, informs, Vol. 3 No. 3, pp. 398-427.

Orlikowski, W.J. and Scott, S.V. (2008), "10 Sociomateriality: Challenging the Separation of Technology, Work and Organization", The Academy of Management Annals, Vol. 2 No. 1, pp. 433-474.

Parmigiani, A. and Howard-Grenville, J.A. (2011), "Routines Revisited: Exploring the Capabilities and Practice Perspectives", The Academy of Management Annals, Vol. 5 No. 1, pp. 413-453. 
Pentland, B.T. and Feldman, M.S. (2005), “Organizational routines as a unit of analysis”, Industrial and Corporate Change, Vol. 14 No. 5, pp. 793-815.

Pentland, B.T. and Feldman, M.S. (2008), "Designing routines: On the folly of designing artifacts, while hoping for patterns of action", Information and Organization, Vol. 18 No. 4, pp. 235-250.

Pentland, B.T., Feldman, M.S., Becker, M.C. and Liu, P. (2012), "Dynamics of Organizational Routines: A Generative Model”, Journal of Management Studies, Vol. 49 No. 8, pp. 1484-1508.

Pentland, B.T., Recker, J. and Wyner, G. (2017), “A thermometer for interdependence: Exploring patterns of interdependence using networks of affordances", presented at the International Conference on Information Systems, pp. 1-13.

Peteraf, M., Di Stefano, G. and Verona, G. (2013), "The elephant in the room of dynamic capabilities: Bringing two diverging conversations together", Strategic Management Journal, John Wiley and Sons, Ltd, Vol. 34 No. 12, pp. 1389-1410.

Rietveld, E. and Kiverstein, J. (2014), “A Rich Landscape of Affordances”, Ecological Psychology, Routledge, Vol. 26 No. 4, pp. 325-352.

Romme, A. G. L. (2003), Making a Difference: Organization as Design. Organization Science, Vol. 14 No. 5 , pp. 558-573. http://doi.org/10.1287/orsc.14.5.558.16769

Schön, D. A. (1983), Reflective Practitioner: How Professionals Think in Action. BasicBooks, New York.

Simone. (2018), "Organizational routine design in a hospital: a narrative-based study of ostensive routine dimensions in the making", presented at the PROS, pp. 1-30.

Simpson, B. and Lorino, P. (2016), "Re-viewing Routines Through a Pragmatist Lens", in Organizational Routines, Oxford University Press, pp. 1-37.

Spee, P. and Jarzabkowski, P.A. (2017), "Agreeing on What? Creating Joint Accounts of Strategic Change”, Organization Science, Vol. 28 No. 1, pp. 152-176.

Sutton, R.I. and Staw, B.M. (1995), "What Theory is Not", Administrative Science Quarterly, Vol. 40 No. 3 , p. 371.

Teece, D.J. (2007), "Explicating dynamic capabilities: the nature and microfoundations of (sustainable) enterprise performance”, Strategic Management Journal, Vol. 28 No. 13, pp. 1319-1350.

van Aken, J.E. and Romme, A.G.L. (2009), "Reinventing the future: adding design science to the repertoire of organization and management studies", Organization Management Journal, Vol. 6 No. 1, pp. 5-12.

van Hulst, M. and Tsoukas, H. (2018), "Patterning Practice: Stability and Change Over Time in a Teaching Routine", presented at the 10th International Symposium on Process Organization Studies, Halidiki, Greece.

Yanow, D. and Tsoukas, H. (2009), What is Reflection-In-Action? A Phenomenological Account. Journal of Management Studies, Vol. 46 No. 8, pp.1339-1364. http://doi.org/10.1111/j.1467-6486.2009.00859.x

Yin, R. K. (2013), Case Study Research: Design and Methods. SAGE Publications.

Yoo, Y., Boland, R.J., Jr. and Lyytinen, K. (2006), "From Organization Design to Organization Designing", Organization Science, Vol. 17 No. 2, pp. 215-229.

\section{ACKNOWLEDGMENTS}

We want to acknowledge the help of several people that have been crucial in developing the ideas of this paper. On the one hand we have to thank the help of the company where our master student was able to do her graduation. Here specifically the mentoring of Katinka Bergema and Monique de Leeuw has been crucial.

The paper has gained much through the fruitful discussions at PROS 2018 and the Practice and Process Summer school at Warwick University, we want to thank the participants for their help. We also want to thank the many discussions we have with routine scholars, specifically the kind help of Katharina Dittrich and Brian Pentland, who have substantiated the ideas around routine design by bringing in the appropriate literature. Besides these, we would also like to thank the help of Fleur Deken, Waldemar Kremser, and Hans Berends who have aided the discussions early on around designing organizations and organizational processes. Last, but not least, the paper has gained much from the many discussions with Yan Feng. 